\title{
When Does Magma Break?
}

\author{
Fabian B. Wadsworth, Taylor Witcher, Jérémie Vasseur, \\ Donald B. Dingwell and Bettina Scheu
}

\begin{abstract}
Geophysical signals arriving at the Earth's surface originate from a source mechanism at depth but are not necessarily directly observable. Therefore, well-posed experiments can provide insights into source mechanics and, importantly, the parameters required to model aspects of the sources of unrest signals. In this Chapter we detail one such example of how experimental laboratory work has improved our understanding of unrest signals. We focus on the failure of single- and multi-phase magmas, demonstrating that the liquid viscosity, and therefore the temperature and volatile content of a magma of a given composition, is the limiting parameter in determining whether a magma will ascend viscously or whether it can fracture during ascent. This critical threshold is characterized by a Deborah number, the ratio of the timescale of relaxation to the timescale of local flow. We show that for single-phase magmatic liquids and for vigorously vesiculating magmas, a local Deborah number of $10^{-2}$ is the limit above which mixed viscoelastic behaviour including fracture propagation can be expected, and a Deborah number of 1 is the limit above which magma is dominantly elastic and responds in a brittle manner to applied stresses. These thresholds can be understood in terms of the onset and peak of the Debye relaxation process for viscoelastic liquids. The apparent validity of a Maxwell model permits us to predict the maximum stress that can be supported by a volcanic liquid deforming in the high Deborah number range. We use these constraints to provide a map of timescales on which we contour dominant system responses from viscous to purely brittle; valid for all magmatic liquids. Finally, we explore the scaling necessary to extend these conceptual insights to crystal- and bubble-bearing magmas valid under specific conditions.
\end{abstract}

F.B. Wadsworth $(\bowtie) \cdot$ T. Witcher $\cdot$ J. Vasseur

D.B. Dingwell · B. Scheu

Ludwig-Maximilians-Universität, Theresienstr.41,

80333 Munich, Germany

e-mail: fabian.wadsworth@min.uni-muenchen.de

Advs in Volcanology (2019) 171-184

DOI 10.1007/11157_2017_23

(C) The Author(s) 2017

Published Online: 18 October 2017 
The competing timescales of deformation and relaxation in magma are relevant to unrest source mechanisms that originate from magma deformation, such as long-period seismic signals that are used to predict eruption timing.

\section{Keywords}

Rheology - Strain rate - Experimental volcanology - Glass transition • Failure forecasting $\cdot$ Low frequency earthquakes $\cdot$ Viscous dissipation

\section{Glossary}

Rheology

The study of the response of a material to an applied stress or deformation. In the volcano-sciences this typically refers to magma-rheology which is dominated by the rheology of the liquid phase (a viscous or viscoelastic melt) and the additional effect of suspended phases (crystals and gases).

Viscoelasticity A material response to an applied stress in which both elastic and viscous components of the deformation are observed. In magma, as the temperature decreases or the local strain rate increases, the elastic component becomes more dominant. When the viscous component is negligible, purely elastic behaviour and material-rupture can readily occur. See Rheology.

\section{Introduction}

There are a wide variety of observable unrest signals at active volcanoes. The key unrest signals are those that are diagnostic of a new regime of behaviour or of how the system may evolve in the future. One such family of events are the low-frequency earthquakes at volcanoes, which are thought to directly represent magma movement at moderate to shallow depths (Chouet et al. 1994; Chouet 1996; Neuberg et al. 2006; Salvage and Neuberg 2016). Such events are powerful tools particularly because they are closely associated with surface activity (Miller et al. 1998). Accelerating event rates of low frequency earthquakes can be used to retrospectively predict an eruption or dome collapse event with reasonable accuracy (Salvage and Neuberg 2016). The utility of the low-frequency event type has been solidified since physical hypotheses for the source mechanism have been put forward (Neuberg et al. 2006) and tested in scaled laboratory expeirments (Benson et al. 2008; Tuffen et al. 2008). The phenomenological observation of the use of certain signal types over others is useful and has led to accurate retrospective eruption forecasts (Voight 1988; Chouet 1996). However, knowledge of the physics of the source leads to a more diverse range of tools being deployed to understand the evolution of volcanic systems into the future. In the context of low-frequency earthquakes at volcanoes, once a 
source mechanism is identified (Tuffen et al. 2003; Neuberg et al. 2006), numerical models of magma ascent in the conduit beneath volcanoes can be used to reproduce the depths of the source from first principles (Thomas and Neuberg 2012) and could eventually make forecasts of other observables at the surface that would be consistent with impending eruption.

In this Chapter we explore the source mechanism of low-frequency earthquakes at volcanoes from a physical perspective using a compilation of data from scaled laboratory experiments. We use these datasets to demonstrate that the critical threshold for fracture propagation in a viscoelastic fluid such as magma is universal. We propose that this potentially simplifies the inputs required for effective modelling of source mechanics of low-frequency events. More than this, we hope that this provides a good example of how laboratory work can provide valuable insight into the physical feasibility of models proposed to explain unrest signals at volcanoes.

\section{Scaling the Viscous-to-Brittle Transition in Magmas}

\subsection{Single-Phase Magmatic Liquids}

Newtonian viscous liquids deform and flow under applied stresses such that the rate of shear strain $\dot{\gamma}$ resulting from an applied shear stress $\tau$ is proportional to the viscosity $\mu$ via $\tau=\mu \dot{\gamma}$. However, as large shear stresses are applied to viscous liquids, they can exhibit viscoelastic behaviour, which manifests as an apparent non-Newtonian relationship between $\tau$ and $\dot{\gamma}$ and can result in fracture propagation locally in the liquid. Of interest here is the transition from simple, apparently Newtonian viscous behaviour to complex viscoelastic behaviour.

Maxwell described the simplest viscoelastic model in which a liquid has a characteristic time required to relax an applied shear stress, termed the Maxwell relaxation timescale $\lambda_{r}$, which is given by $\lambda_{r}=\mu / G_{\infty}$ where $G_{\infty}$ is the shear modulus in the purely elastic regime. The Maxwell model of viscoelasticity permits us to predict that if a shear strain is imposed on a viscoelastic liquid, the resultant shear stress will rise rapidly to a peak value $\tau_{i}$ and will relax over time $t$ according to $\tau(t)=\tau_{i} \exp \left(-t / \lambda_{r}\right)$. This simple concept has proved powerful in describing the transition between Newtonian and viscoelastic behaviour in volcanic liquids (Dingwell 1995, 1996). Indeed, this model is invoked to explain the transition between volcanic liquids and volcanic glasses on cooling (e.g. Stevenson et al. 1995), the fragmentation of fluid and bubbly magma undergoing decompression (Alidibirov and Dingwell 1996; Kameda and Kuribara 2008) and the conditions under which extensive shear fracture networks can form at or near volcanic conduit margins (Gonnermann and Manga 2003; Tuffen et al. 2003; Kendrick et al. 2014; Hornby et al. 2015). In all cases, it is useful to define a Deborah number De, which is the dimensionless ratio between the Maxwell relaxation time and the timescale of deformation $\lambda$. For simple (viscometric) shearing flow, the latter timescale is $1 / \dot{\gamma}$ and thus

$$
\mathrm{De}=\frac{\lambda_{r}}{\lambda}=\frac{\mu \dot{\gamma}}{G_{\infty}}
$$

Our hypothesis is that a Deborah number of unity separates the regime between viscous $($ De $\ll 1)$ and elastic (De $\gg 1)$ responses to shear stresses, or equivalently, between a system that can relax shear stresses efficiently from one in which shear stresses can accumulate elastically. In two different experimental types, both Webb and Dingwell (1990a) and Cordonnier et al. (2012a, b) showed that in fact the first evidence of behaviour that is not purely viscous occurs at $\mathrm{De} \geq 10^{-2}$ and not exactly at unity. This observation will be discussed later.

The power of Eq. 1 is that simple parameters that can be measured in the laboratory can be used to predict where this transitional point of De $=1$ will be. This critical Deborah number can be termed $\mathrm{De}^{\prime}$. In what follows, we give examples of how $\mu$ and $G_{\infty}$ have been found for a range of volcanic liquid compositions at magmatic temperatures and volatile contents before exploring the validity and applicability of the 
scaling in Eq. 1. The dimensionless nature of Eq. 1 means that it can be assessed for any system so long as $\lambda$ can be defined.

At the core of the experimental toolkit is the determination of the fundamental quantities that are required to model volcanic processes involved in unrest. The most variable physical quantity in volcanic systems is the viscosity of the liquid phase. Using a range of techniques, this viscosity can be determined with prodigious accuracy and significant effort has been expended in mapping the full range of composition, temperature (see Giordano et al. 2008) and volatile content (Hess and Dingwell 1996) relevant to shallow magmatic settings. Multicomponent models have been proposed such that the viscosity of any composition of silicate volcanic liquid on Earth can now be predicted as a function of temperature including the range of conditions between shallow magma storage and the surface (Hess and Dingwell 1996; Giordano et al. 2008). This provides parameterization of $\mu(T)$ for use in Eq. 1. The most commonly used form for $\mu(T)$ is the non-Arrhenian Vogel-Fulcher-Tammann equation of the form

$$
\mu=A \exp \left(\frac{B}{T-C}\right),
$$

where $A, B$, and $C$ are coefficients that are experimentally determined and then parameterized as a function of families of oxides in the liquid structure (Giordano et al. 2008) or as a function of the dissolved water content (for calc-alkaline rhyolites: Hess and Dingwell 1996), to give two examples.

To give examples of the range of viscosities of interest in volcanic scenarios, we give end members in Fig. 1 for a calc-alkaline rhyolite using the model from Hess and Dingwell (1996), and for the basaltic liquid composition provided in Zhang et al. (1991) using the model from Giordano et al. (2008), both contoured for a range of water contents.
Unlike viscosity, the shear modulus in the elastic regime does not vary significantly in siliciate liquids and is not strongly dependent on composition or temperature. Indeed, a short survey of the values for $G_{\infty}$ in silicate glasses and liquids at a range of temperature and a huge range of composition, provided by Dingwell and Webb (1989) shows that $G_{\infty}=10^{10 \pm 0.5} \mathrm{~Pa}$. Here we use this range in order to fully parameterize De (by predicting $\lambda_{r}$ ) as a function of temperature (via Eq. 2) for any silicate liquid in the shallow crust.

\subsection{Extensions to Multiphase Magmas}

Except in rare circumstances such as obsidian-forming eruptions, volcanic liquids are not often erupted without some proportion of suspended pore space (either as isolated bubbles or connected networks) and rigid crystals. In either case, the utility of Eq. 1 requires additional attention. We posit that for the liquid phase between the pores or the crystals, De given by Eq. 1 holds. However, we acknowledge that estimation or measurement of the rate of shear strain locally between pores or crystals would be difficult (Deubelbeiss et al. 2011). Therefore, a more robust criterion for the viscous-to-brittle transition in crystal- or bubble-bearing magma would require that we scale the bulk strain rate $\dot{\gamma}_{b}$ on the system for the effect of the suspended load.

For crystals, we show some first-order scaling attempts for their effect on the critical threshold for the onset of brittle behaviour in multiphase magma. The simplest view of the local flow of liquid in crystal-bearing magma under constant shear stress is that the rate of shear strain between the crystals should scale approximately with $\dot{\gamma}=$ $\dot{\gamma}_{b}\left(1-\phi_{x} / \phi_{m}\right)^{-1}$ where $\phi_{x}$ is the suspended crystal volume fraction and $\phi_{m}$ is a jamming fraction above which no more crystals can be 


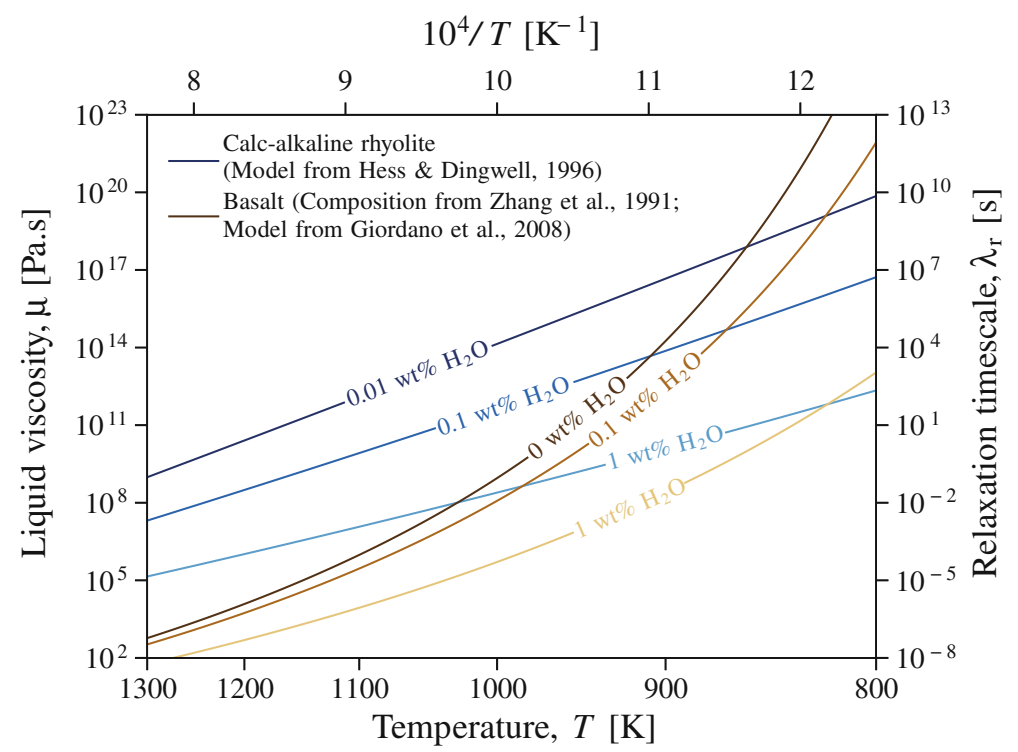

Fig. 1 The viscosity of end-member magmatic liquids with variable dissolved water concentrations. Plotted are the results for calc-alkaline rhyolite from the general viscosity model for hydrous silicic liquids (Hess and Dingwell 1996) for 0.01-1 wt\% water, and a typical basaltic composition (composition from Zhang et al.

added to the flowing system. This scaling would imply that the Deborah number for a crystal-bearing magma $\mathrm{De}_{\mathrm{x}}$ would be

$$
\mathrm{De}_{\mathrm{x}}=\frac{\mu}{G_{\infty}} \dot{\gamma}_{b}\left(1-\frac{\phi_{x}}{\phi_{m}}\right)^{-1},
$$

where $\phi_{m}$ is a function of crystal shape and roughness (Mueller et al. 2010; Mader et al. 2013). A critical value of $\mathrm{De}_{\mathrm{x}}$, termed $\mathrm{De}_{x}^{\prime}$, is $10^{-2}$, consistent with the limiting $\mathrm{De}^{\prime}$ at $\phi=0$. A new definition of the bulk failure criterion $\mathrm{De}^{\prime}$ can now be made, which decreases as $\phi \rightarrow \phi_{m}$ so that $\operatorname{De}^{\prime}=\operatorname{De}_{x}^{\prime}\left(1-\phi_{x} / \phi_{m}\right)$. In Fig. 2 we demonstrate how this concept predicts a linear relationship between $\mathrm{De}_{\mathrm{x}}$ and $\phi_{x} / \phi_{m}$, which in turn shows that lower bulk strain rates are required to induce brittle behaviour in crystal-bearing magmas.

This hypothesis was found to hold for simple two-phase systems by Cordonnier et al. (2012a), but where those authors required that $\mu$ be replaced by the suspension viscosity of the whole
1991) calculated using the multicomponent viscosity model (Giordano et al. 2008) for $0-1$ wt $\%$ water. The relaxation timescale is calculated assuming a composition independent value for $G_{\infty}$ of $10^{10} \mathrm{~Pa}$ (Dingwell and Webb 1989)

system, which is at odds with the scaling of strain rate for local liquid effects only. Nonetheless, this approach described their data satisfactorily and the conceptual insight that crystals locally increase the liquid rate of shear strain relative to the bulk value is robust, with the implication is that the whole suspension will begin fracturing at lower bulk rates of strain relative to a single-phase liquid of the same composition as crystals are added. It may be that additional second-order effects are important at high $\phi_{x}$, which are not accounted for in this simple analysis.

For the case of porous magmas, there are two considerations: (1) The growth of bubbles exerts a rate of shear strain in the liquid concentrated at the bubble walls, which is broadly independent of any bulk shearing deformation, and (2) like for the crystal case, the presence of bubbles changes the partitioning of the bulk rate of shear strain in the liquid between the bubbles. In the case of scenario (1), the Rayleigh-Plesset equation can be used to relate the bubble growth rate to the gas 
Fig. 2 The critical Deborah number required for fracturing $\mathrm{De}^{\prime}$ is reduced when crystals are suspended in magma. To a first-order, the $\mathrm{De}^{\prime}$ value is reduced proportional to $\operatorname{De}^{\prime}=\operatorname{De}_{\mathrm{x}}^{\prime}\left(1-\phi_{x} / \phi_{m}\right)$

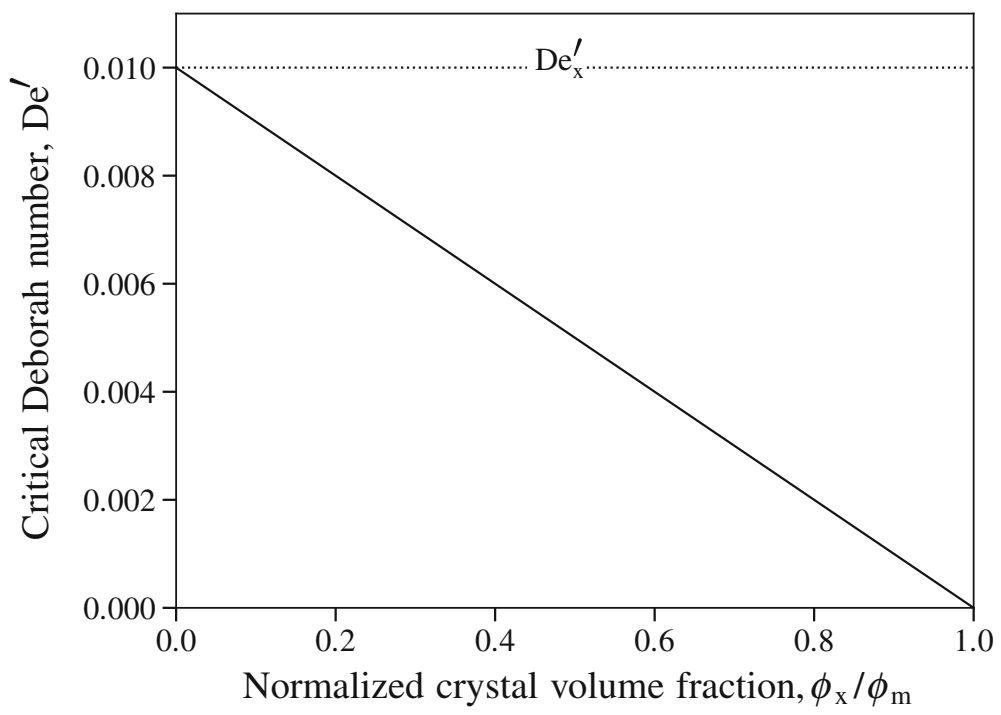

pressure in the bubble, relative to the hydrostatic pressure (Sparks 1978). This can be augmented for the diffusion-controlled gradient of viscosity in the immediate liquid shell around a growing bubble (Prousevitch et al. 1993; Lensky et al. 2001). The component of the rate of shear strain tangential to the bubble wall $\dot{\gamma}_{\theta}$ can then be computed throughout bubble growth (Ichihara et al. 2002). If we were then to input $\dot{\gamma}_{\theta}$ into our computation of De, we would predict under which conditions the system would meet the criterion of $\mathrm{De}^{\prime}=10^{-2}$ locally at the bubble rim. These conditions would be best cast in terms of the critical rate of pressure or temperature change, or bulk initial volatile content that would allow the bubble to grow sufficiently fast that fractures could be propagated at the bubble wall.

In case (2), the effect of bubbles on the bulk Deborah number is less clear. We speculate that at De $\gg 1$, the stress required to fracture a bubbly system will be analogous to that required to fracture a vesicular glass. In this case, models for the effect of spherical cavities on the stress required for fracturing are valid and they predict that the stress is reduced significantly as the bulk gas volume fraction increases (Sammis and Ashby 1986). This has been confirmed in the high Deborah number regime for porous liquids analogous to volcanic systems (Vasseur et al.
2013) but remains untested in the low Deborah number regime where bubble deformation may be important.

\subsection{Apparent Non-newtonian Effects}

In single-phase liquids at Deborah numbers below the critical threshold at which fracturing is observed, there is evidence that during steady state shearing flow, there is a non-Newtonian relationship between applied shear stress and resultant shear rate of strain (Simmons et al. 1982; Dingwell and Webb 1989; Webb and Dingwell 1990a; Cordonnier et al. 2012b). In the onset of this non-Newtonian, the onset of this non-Newtonian behaviour appears to be well described by the value above which viscous dissipation of heat is active on the system length scale of interest (Costa and Macedonio 2005; Hess et al. 2008). This can be scaled by the Brinkman number $\mathrm{Br}$

$$
\mathrm{Br}=\frac{\Phi_{g}}{\Phi_{l}}=\frac{\mu \dot{\gamma}^{2}}{k q},
$$

where $\Phi_{g}$ and $\Phi_{l}$ are the gain and loss power densities, respectively, $q$ is the areal heat flux out of the system and $k$ is the thermal conductivity of 
the material. $\Phi_{g}=\mu \dot{\gamma}^{2}$ represents the amount of energy produced in a system of a given volume by viscous dissipation of heat, while $\Phi_{l}=k q$ represents the energy lost due to diffusive thermal equilibration. When $\mathrm{Br} \gg 1$, heat is efficiently produced and inefficiently lost from the system, resulting in a bulk temperature increase in the liquid. This would manifest itself as an apparent shear thinning rheology if the temperature increase where not locally accounted for, and would be most likely to be operative at high viscosities and high shear strain rates. We note that unlike the Deborah number, the Brinkman number is scale dependent (as $q$ depends on the area available for heat transfer out of the system) and so should be assessed for each system scale separately.

\section{The Universal Breaking Timescales of Volcanic Liquids}

Laboratory data related to the viscous-to-brittle transition in magmas has been collected in a variety of geometries. Using single-phase liquids, there are two dominant geometries: (1) thin fibers of silicate liquid of basaltic, andesitic, phonolitic and rhyolitic composition were stretched under constant load in tension until the fibers snapped in a singular fracture event (Webb and Dingwell 1990b), and (2) cylinders of synthetic borosilicate liquid were compressed under constant load and the bulk temporal evolution of the rate of axial shortening was determined as viscous (relaxed) if it continuously increased to a steady or near-steady value, or brittle (unrelaxed) if the axial shortening rate jumped due to fracturing events (Cordonnier et al. 2012b). In another type of experiment, analogue vesicular liquids were decompressed at different rates from pressure (Kameda and Kuribara 2008; Kameda et al. 2013). In this type of decompression experiment, if the dominant response was viscous (relaxed), then the sample was seen to grow due to decompression-driven bubble growth, and if the dominant response was brittle (unrelaxed), then smooth sample inflation was punctuated by visible fractures opening. In these decompression experiments there additionally was a violent rupture mode in which the fracturing was pervasive and shattered the sample in a vigorous fragmentation event. These data are selected here because the liquids used have a known relaxation time under the conditions used in the experiments and care was taken by the authors who originated the work to investigate the shear rates of strain local to the bubbles (discussed above).

In Fig. 3 we map these experimental results as a ratio of the deformation timescale to the relaxation timescale, which permits us to contour the plot for critical Deborah numbers. We colour-code the data according to the bulk mode of response of the sample to the deformation using green to represent purely viscous relaxed behaviour, orange to represent brittle unrelaxed behaviour and red to represent the complete violent rupture of the sample. These data suggest that the viscous relaxed behaviour transitions to unrelaxed brittle behaviour at a Deborah number of $10^{-2}$, and are consistent across a huge range of experimental conditions and across both the single-phase compression and vesicular decompression experiment types. Furthermore, we see that a Deborah number of unity consistently separates the experiments for which the bulk response was unrelaxed and brittle from those for which the response was violent rupture, fragmentation or complete failure. It appears that these two thresholds, $\mathrm{De}=10^{-2}$ and $\mathrm{De}=1$ are universal even when comparing analogue room temperature liquids with high temperature silicate liquids deformed in a variety of ways. This lends power to the scaling provided by the dimensionless Deborah number and implies that we need only to define the liquid viscosity and a characteristic rate of deformation in order to predict whether a system will flow viscously or rupture violently. For example, the working viscosity of the analogue fluid used in Kameda and Kuribara (2008) is $10^{0} \leq \mu \leq 10^{10} \mathrm{~Pa}$.s, which extends to much lower used in Cordonnier et al. (2012b), and yet the scaling with the Deborah number 


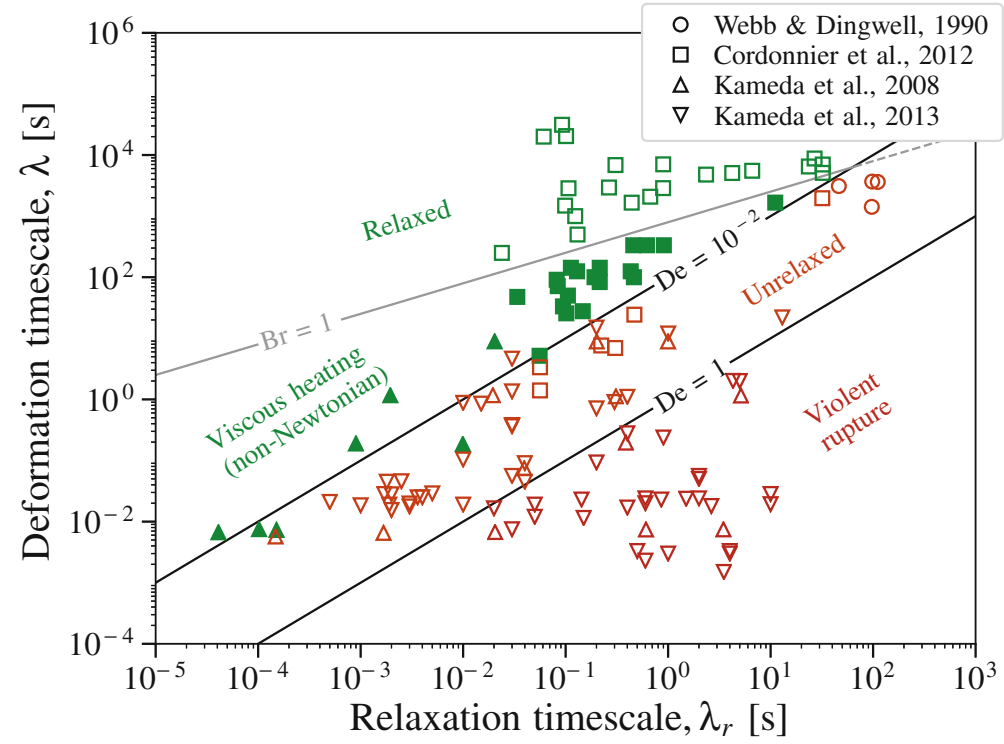

Fig. 3 A map of behaviour arising from deformation experiments on natural (Webb and Dingwell 1990b) and synthetic (Cordonnier et al. 2012b) silicate liquids and on analogues of magmatic liquids undergoing vesiculation (Kameda and Kuribara 2008; Kameda et al. 2013). The experimental results were obtained by applying a characteristic timescale of deformation $\lambda$ of a liquid with a characteristic timescale of stress relaxation $\lambda_{r}$. Marked are ratios $\lambda_{r} / \lambda$, equivalent to Deborah numbers De, of $10^{-2}$

holds across a broad range simply because the deformation timescale was also smaller in the former example.

In the viscous field, Cordonnier et al. (2012b) additionally recorded whether samples hosted a measurable temperature increase due to viscous dissipation of heat during the experiment, or not. In Fig. 3, we plot those with a measureable temperature increase as filled symbols and those without this feature as unfilled symbols. To explain this, we plot the threshold dimensionless Brinkman number of unity $\mathrm{Br}=1$, using an estimation of the loss power density for the furnace and sample size used $\Phi_{l}=10^{4.5} \mathrm{~W} . \mathrm{m}^{-2}$ (Cordonnier et al. 2012b). We note that the Brinkman number curve consistently divides the regimes of purely isothermal experiments and those with measurable heat gain. On this map, the position of $\mathrm{Br}=1$ is non-unique and depends on sample size, such that on the scale of a volcanic conduit, for example, $\mathrm{Br}=1$ would occur and 1, which separate experiments with a purely viscous response from those with an unrelaxed brittle response or a violent rupture response, respectively. Additionally marked is the Brinkman number $\mathrm{Br}$ of 1 , which separates the boundary between isothermal viscous behaviour (above the line) and viscous behaviour in which the material heats up due to viscous dissipation as heat (below the line)

at much higher deformation timescales for the same relaxation timescale (the curve would shift up in Fig. 3). This implies that in the natural case, viscous dissipation of heat may be far more important than shown here for the sample length scale (Costa and Macedonio 2005; Mastin 2005; Costa et al. 2007). Nevertheless, the Deborah number limits discussed appear to be universal and, importantly, are scale-independent.

To gain helpful physical insight into why $10^{-2} \leq \mathrm{De} \leq 10^{0}$ is the transitional window between a purely viscous and a purely elastic response of a liquid to a deformation, we provide low-strain, high frequency oscillatory rheological measurement data for similar liquids (Fig. 4). Here, rods of single-phase liquid are subjected to a low-amplitude oscillatory strain with a forcing frequency $\omega$ at a range of temperatures similar to those used in experiments presented in Fig. 2. Here, $\omega$ is normalized with $\lambda_{r}$, yielding a dimensionless frequency or, equivalently, a 


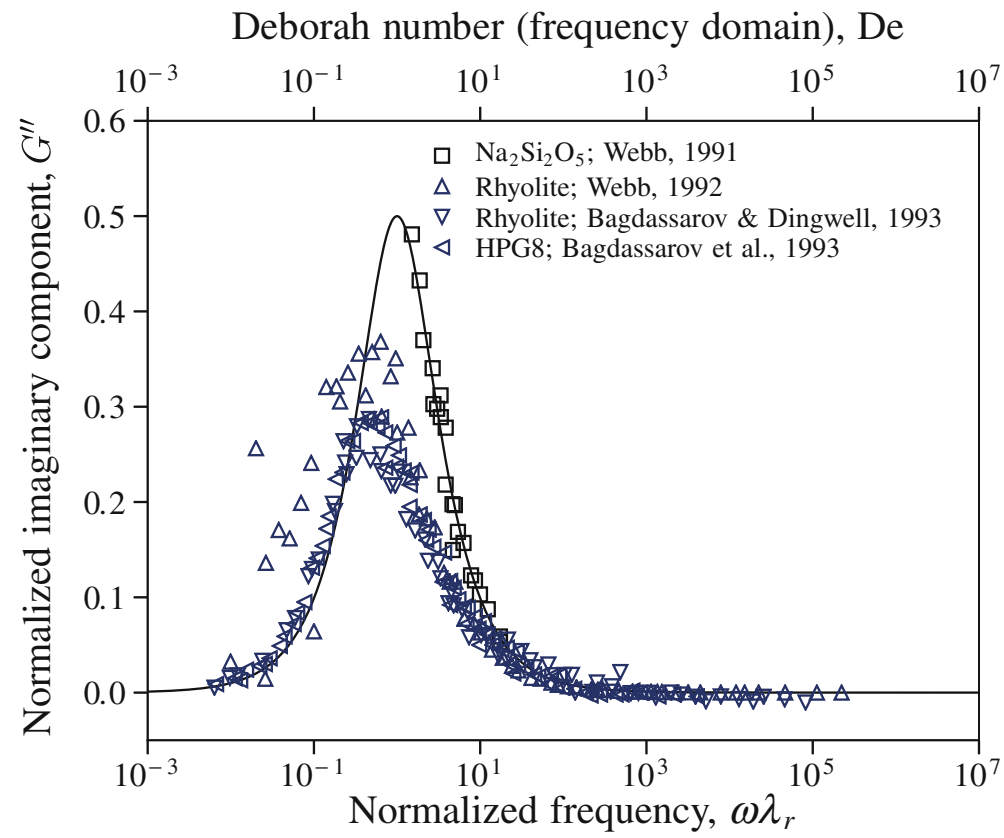

Fig. 4 The response of synthetic (Webb 1991; Bagdassarov and Dingwell 1993a) and natural (Webb 1992; Bagdassarov and Dingwell 1993b) silicate liquids to low strain, high frequency oscillatory deformation tests. This is shown as a normalized imaginary component of the

frequency-domain version of the Deborah number. The metric that we choose to track is the imaginary component of the complex elastic modulus $G^{\prime \prime}$ normalized by $G_{\infty}$. When this value $G^{\prime \prime} / G_{\infty}$ is close to zero in the low Deborah number limit, the system is dominated by liquid behaviour and when it rises from zero at increasing Deborah number, there is an increasing component of the response to the forced oscillation that is elastic. We present collated data for a sodium disilicate synthetic composition (Webb 1991), rhyolitic compositions (Webb 1992; Bagdassarov and Dingwell 1993b) and a synthetic composition used as an analogue for type calc-alkaline rhyolite systems (Bagdassarov and Dingwell 1993a). This imaginary component can be described by the generalized Debye model for viscoelasticity for systems with a single characteristic relaxation time as $G^{\prime \prime}=\omega \lambda_{r} /$ $\left[\left(\omega \lambda_{r}\right)^{2}+1\right]$. The data reproduce the broad shape of the Debye model, albeit with an shear modulus $G^{\prime \prime} / G_{\infty}$ as a function of the frequency of applied oscillation normalized by the relaxation timescale $\omega \lambda_{r}$, which is equivalent to a Deborah number De in the frequency domain. We show the viscoelastic prediction for a Maxwell liquid for comparison (solid curve)

overprediction of $G^{\prime \prime}$ around $\omega \lambda_{r} \sim 1$ for the rhyolitic liquids, which is poorly understood. Nevertheless, we point out that the first onset of a measurable elastic component to the response of the liquid to deformation occurs at $\mathrm{De}=\omega \lambda_{r} \approx 10^{-2}$. Similarly, the point above which the majority of the response to deformation is elastic (the peak of $G^{\prime \prime}$ ) occurs at De = $\omega \lambda_{r} \approx 1$ (Fig. 3). We use this observation to validate the two thresholds found in Fig. 3. This implies that fractures can propagate in silicate liquids when there is even a small component of elastic behaviour ( $\mathrm{De} \geq 10^{-2}$ ) and that those fractures can propagate vigorously when the elastic behaviour dominates over the viscous behaviour ( $\mathrm{De} \geq 1)$. An interpretation might also be that $10^{-2} \leq \mathrm{De} \leq 1$ is the range in which fracture propagation is competing with viscous relaxation of stress and therefore the fractures are unlikely to be long, sharp-tipped or pervasive. And that at $\mathrm{De} \geq 1$, stress dissipation by fracture 
propagation can be localized onto longer, sharp and pervasive fracture networks.

The fact that a viscous limit to the expansion of vesicular magma also scales with our Deborah number criterion is tantalizing. Microphysically, in this case it is not fracture of a deforming homogeneous liquid, but fractures propagating at bubble walls as the local rate of strain in the liquid induced by expansion of the bubble meets the Deborah number criterion for fracture propagation (c.f. Kameda and Kuribara 2008). For complete rupture of the vesicular materialwhich is a fragmentation event or violent rupture in Fig. 3-the fractures propagating from the bubbles must interact. Presumably in the range $10^{-2} \leq \mathrm{De}<1$, fractures propagate but the fracture tips are blunted during competing viscous relaxation such that brittle behaviour can be observed but is not catastrophic to the system. Then, as the local strain rate at the bubble wall increases further and De approaches 1, the fractures propagate in a dominantly elastic medium and can span the inter-bubble distances, interacting to produce violent rupture. Therefore, it is clear that a scaling of the Deborah number concept to bubble wall dynamics would provide a fragmentation criterion for viscoelastic vesiculating magma (c.f. Namiki and Manga 2005; Koyaguchi et al. 2008; Namiki and Manga 2008).

\section{Laboratory-Scale Unrest Signals}

When magma breaks in a laboratory experiment, acoustic emissions - packets of acoustic energy - are released and can be recorded (Benson et al. 2008; Lavallee et al. 2008). These signals appear to represent large total released amounts of energy when $\lambda$ is short (high $\dot{\gamma}$ ), compared to when $\lambda$ is long (low $\dot{\gamma}$ ) (Lavallee et al. 2008). This supports our posit that fracture networks are more likely to be pervasive and large when De is large than when De is small. For single phase silicate liquids deformed at high De, Tuffen et al. (2008) showed that the experimental acoustic event frequency range and sample fracture length scale scaled with natural constraints of in-conduit volcanic fracture systems and natural frequencies of low-frequency volcano-seismicity, indicating that these viscoelastic fracturing events are indeed the likely source mechanism for low-frequency earthquakes at volcanoes. This confirmed the conclusion of Neuberg et al. (2006), who showed that these low-frequency events were most likely to be associated with repetitive fracturing of magma at a given depth in the conduit during ascent. Neuberg et al. (2006) further modelled magma ascent in confined geometry and showed that a De $\sim 1$ is met at a depth of $830 \mathrm{~m}$ below the surface using parameters typical for recent eruptions at Soufriere Hills volcano and the magma thereof. Thomas and Neuberg (2012) predicted a deeper source of $1500 \mathrm{~m}$ using the same model approach but by invoking a conduit restriction (see Chap. 9), consistent with inversions for low-frequency sources using seismic data. Therefore, viscoelastic magma fracturing in the high Deborah number regime appears to be a consistent model for the source mechanics of low-frequency volcano seismicity, often used for eruption forecasting.

Vasseur et al. (2015) showed that the forecastability of full sample rupture scales with the heterogeneity of the system - cast most simply as a porosity (Fig. 5). The implication is that the less vesicular the magma undergoing deformation, the less likely that accurate forecasts based on accelerated precursory signals can be made, with up to $\sim 120 \%$ error on the timing of the rupture event for single-phase homogeneous liquids in the high De limit. It may be that the magma vesicularity, pore-network structure (Vasseur et al. 2017), crystallinity and textural anisotropy, play key roles in determining forecasting success based on low-frequency earthquakes. More experimental work is clearly required in this area, along with more rigorous scaling between acoustic and seismic events that originate from magma failure.

An implication of the models explored here, encapsulated by Eq. 1, is that the peak stress supported by a liquid $\sigma_{m}$ can be predicted as a 


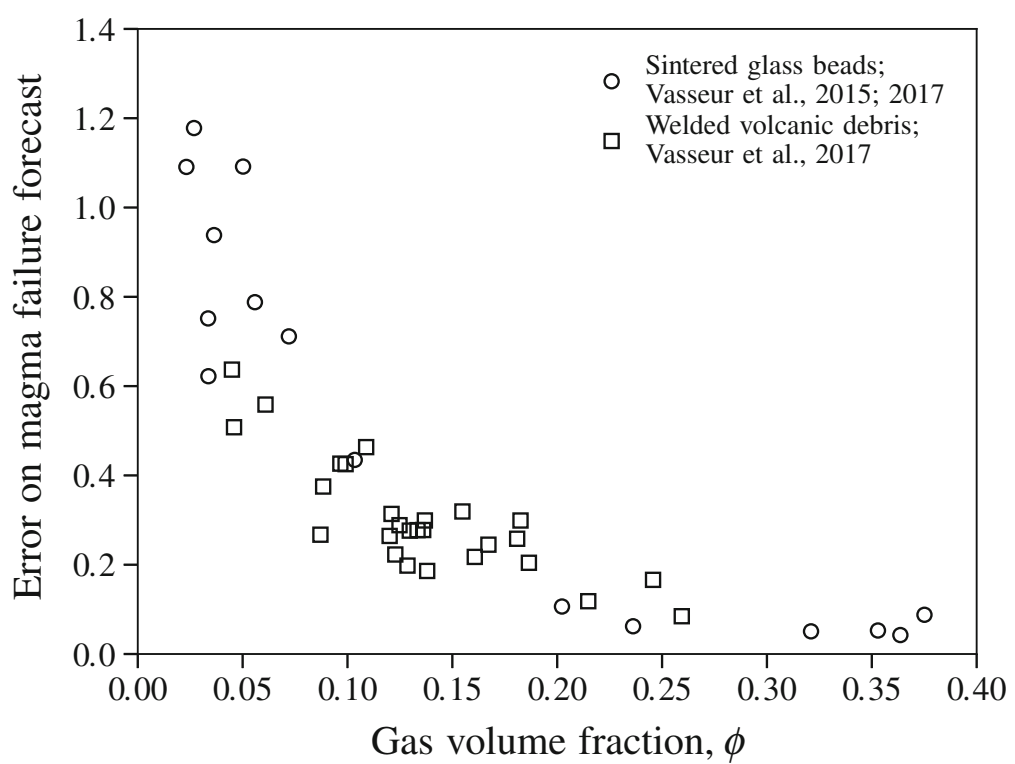

Fig. 5 In the high-De regime, the error on a prediction of failure times scales with the porosity of the material such that low porosity magmas are unpredictable and high porosity magmas are predictable (Vasseur et al. 2015).
The failure times are recorded as a large stress drop during uniaxial loading, and the approach to failure is monitored using acoustic emissions generated by pre-failure micro-fracturing events
Fig. 6 The peak stress that can be supported by a shearing liquid in the low De limit is given by $\sigma_{m}=G_{\infty}$ De. And in the high De limit, this value appears to asymptotically approach $\sigma_{m}=10^{-2} G_{\infty}$ which is equivalent to the strength of glassy materials in that same regime (Simmons et al. 1982)

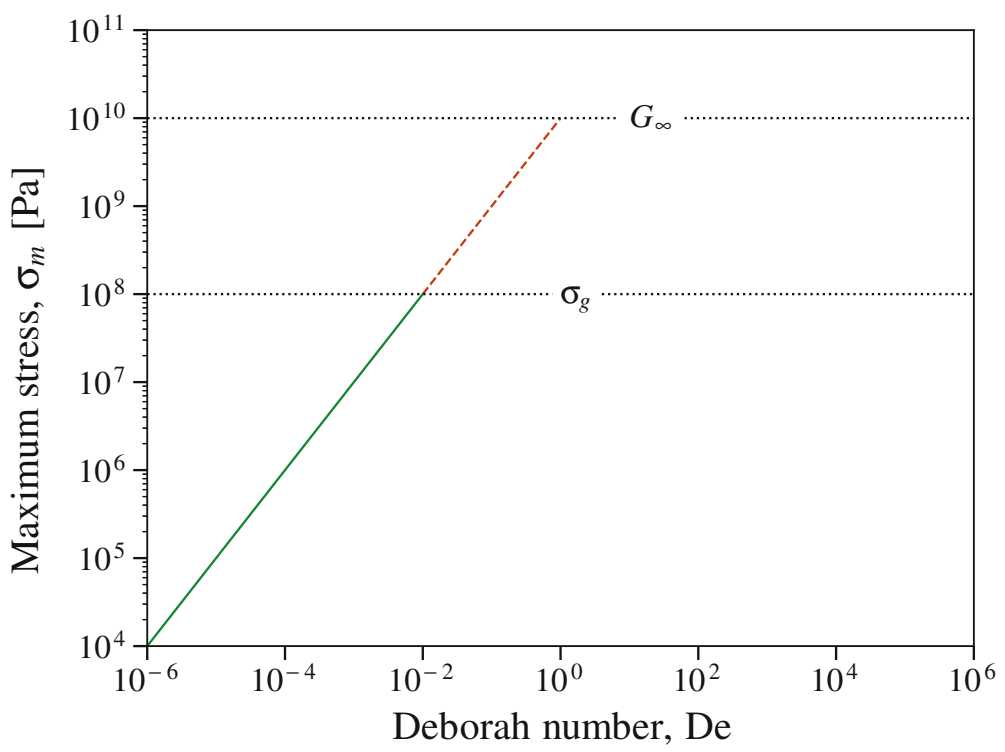

function of De by $\sigma_{m}=G_{\infty}$ De. Once De $\geq 10^{-2}$, however, this linear relationship appears to be invalid as fractures can form in the liquid. It is perhaps significant that the average strength of glass in the high De regime is $\sim 10^{8} \mathrm{~Pa}$ (Simmons et al. 1982; Vasseur et al. 2013), consistent 
with a rupture threshold of $10^{-2} G_{\infty}$. These relationships are explored in Fig. 6.

Here we summarize just one example of how targeted laboratory experiments and dimensional analysis have demonstrated the most likely source mechanism of unrest signals commonly used to monitor magma movement and predict impending eruptions. Clearly, with scaling arguments for the applicability of an experimental set up — such as we show here with the Deborah number analysis-laboratory-based work can provide new insights into unrest mechanisms that facilitate more accurate forward-modelling of geophysical signals.

\section{References}

Alidibirov M, Dingwell DB (1996) Magma fragmentation by rapid decompression. Nature 380:146-148

Bagdassarov N, Dingwell DB, Webb SL (1993) Effect of boron, phosphorus and fluorine on shear stress relaxation in haplogranite melts. Eur J Miner 3:409425

Bagdassarov NS, Dingwell DB (1993) Frequency dependent rheology of vesicular rhyolite. J Geophy Res: Solid Earth 98(B4):6477-6487

Benson P, Vinciguerra S, Meredith P, Young R (2008) Laboratory simulation of volcano seismicity. Science (80-) 322:249-252

Chouet BA (1996) Long-period volcano seismicity: its source and use in eruption forecasting. Nature 380:309-316. doi:10.1038/380309a0

Chouet BA, Page RA, Stephens CD et al (1994) Precursory swarms of long-period events at Redoubt Volcano (1989-1990), Alaska: their origin and use as a forecasting tool. J Volcanol Geotherm Res 62:95135. doi:10.1016/0377-0273(94)90030-2

Cordonnier B, Caricchi L, Pistone M et al (2012a) The viscous-brittle transition of crystal-bearing silicic melt: direct observation of magma rupture and healing. Geology 40:611-614

Cordonnier B, Schmalholz SM, Hess K, Dingwell DB (2012b) Viscous heating in silicate melts: an experimental and numerical comparison. J Geophys Res 117:B02203

Costa A, Macedonio G (2005) Viscous heating effects in fluids with temperature-dependent viscosity: triggering of secondary flows. J Fluid Mech 540:21-38

Costa A, Melnik O, Vedeneeva E (2007) Thermal effects during magma ascent in conduits. J Geophys Res 112: B12205. doi:10.1029/2007JB004985

Deubelbeiss Y, Kaus BJ, Connolly JA, Caricchi L (2011) Potential causes for the non-Newtonian rheology of crystal-bearing magmas. Geochem Geophy Geosys 12(5)
Dingwell DB (1995) Relaxation in silicate melts; some applications. Rev Mineral Geochemistry 32:21-66

Dingwell DB (1996) Volcanic dilemma: flow or blow? Science (80-) 273:1054-1055. doi:10.1126/science. 273.5278.1054

Dingwell DB, Webb SL (1989) Structural relaxation in silicate melts and non-Newtonian melt rheology in geologic processes. Phys Chem Miner 16:508-516

Giordano D, Russell JK, Dingwell DB (2008) Viscosity of magmatic liquids: a model. Earth Planet Sci Lett 271:123-134

Gonnermann HM, Manga M (2003) Explosive volcanism may not be an inevitable consequence of magma fragmentation. Nature 426:432-435

Hess KU, Dingwell DB (1996) Viscosities of hydrous leucogranitic melts: a non-Arrhenian model. Am Mineral 81:1297-1300

Hess K-U, Cordonnier B, Lavallee Y, Dingwell DB (2008) Viscous heating in rhyolite: an in situ experimental determination. Earth Planet Sci Lett 275:121126. doi:10.1016/j.eps1.2008.08.014

Hornby AJ, Kendrick JE, Lamb OD, Hirose T, De Angelis S, Aulock FW, Umakoshi K, Miwa T, Henton De Angelis S, Wadsworth FB, Hess KU (2015) Spine growth and seismogenic faulting at Mt. Unzen, Japan. J Geophys Res: Solid Earth 120(6):4034-4054

Ichihara M, Rittel D, Sturtevant B (2002) Fragmentation of a porous viscoelastic material: implications to magma fragmentation. J Geophys Res: Solid Earth 107(B10)

Kameda M, Kuribara H, Ichihara M (2008) Dominant time scale for brittle fragmentation of vesicular magma by decompression. Geophy Res Lett 35(14)

Kameda M, Ichihara M, Shimanuki S, Okabe W, Shida T (2013) Delayed brittle-like fragmentation of vesicular magma analogue by decompression. J Volcanol Geoth Res 258:113-125

Kendrick JE, Lavallée, Y, Hirose T, Di Toro G, Hornby AJ, De Angelis S, Dingwell DB (2014) Volcanic drumbeat seismicity caused by stick-slip motion and magmatic frictional melting. Nat Geosci 7(6):438

Koyaguchi T, Scheu B, Mitani NK, Melnik O (2008) A fragmentation criterion for highly viscous bubbly magmas estimated from shock tube experiments. J Volcanol Geotherm Res 178:58-71

Lavallee Y, Meredith PG, Dingwell DB et al (2008) Seismogenic lavas and explosive eruption forecasting. Nature 453:507-510. doi:10.1038/nature06980

Lensky NG, Lyakhovsky V, Navon O (2001) Radial variations of melt viscosity around growing bubbles and gas overpressure in vesiculating magmas. Earth Planet Sci Lett 186:1-6

Mader HM, Llewellin EW, Mueller SP (2013) The rheology of two-phase magmas: a review and analysis. J Volcanol Geoth Res 257:135-158

Mastin LG (2005) The controlling effect of viscous dissipation on magma flow in silicic conduits. J Volcanol Geoth Res 143(1):17-28

Miller AD, Stewart RC, White R et al (1998) Seismicity associated wtih dome growth and collapse at the 
Soufriere Hills Volcano, Montserrat. Geophys Res Lett 25:3401-3404

Mueller S, Llewellin EW, Mader HM (2010) The rheology of suspensions of solid particles. Proc $\mathrm{R}$ Soc A Math Phys Eng Sci 466:1201-1228

Namiki A, Manga M (2005) Response of a bubble bearing viscoelastic fluid to rapid decompression: implications for explosive volcanic eruptions. Earth Planet Sci Lett 236(1):269-284

Namiki A, Manga M (2008) Transition between fragmentation and permeable outgassing of low viscosity magmas. J Volcanol Geoth Res 169(1):48-60

Neuberg JW, Tuffen H, Collier L et al (2006) The trigger mechanism of low-frequency earthquakes on Montserrat. J Volcanol Geotherm Res 153:37-50. doi:10. 1016/j.jvolgeores.2005.08.008

Prousevitch AA, Sahagian DL, Anderson AT (1993) Dynamics of diffusive bubble growth in magmas: isothermal case. J Geophys Res Solid Earth 98:2228322307

Salvage R, Neuberg JW (2016) Using a cross correlation technique to refine the accuracy of the Failure Forecast Method: application to Soufrière Hills volcano, Montserrat. J Volcanol Geotherm Res 324:118-133. doi:10.1016/j.jvolgeores.2016.05.011

Sammis CG, Ashby MF (1986) The failure of brittle porous solids under compressive stress states. Acta Metall 34:511-526

Simmons JH, Mohr RK, Montrose CJ (1982) Non-Newtonian viscous flow in glass. J Appl Phys 53:4075-4080

Sparks RSJ (1978) The dynamics of bubble formation and growth in magmas: a review and analysis. J Volcanol Geotherm Res 3:1-37

Stevenson RJ, Dingwell DB, Webb SL, Bagdassarov NS (1995) The equivalence of enthalpy and shear stress relaxation in rhyolitic obsidians and quantification of the liquid-glass transition in volcanic processes. J Volcanol Geotherm Res 68:297-306

Thomas ME, Neuberg J (2012) What makes a volcano tick-a first explanation of deep multiple seismic sources in ascending magma. Geology 40:351-354. doi: $10.1130 / \mathrm{g} 32868.1$

Tuffen H, Dingwell DB, Pinkerton H (2003) Repeated fracture and healing of silicic magma generate flow banding and earthquakes? Geology 31:1089-1092. doi: $10.1130 / \mathrm{g} 19777.1$

Tuffen H, Smith R, Sammonds PR (2008) Evidence for seismogenic fracture of silicic magma. Nature 453:511-514

Vasseur J, Wadsworth FB, Lavallée Y et al (2013) Volcanic sintering: timescales of viscous densification and strength recovery. Geophys Res Lett 40:56585664

Vasseur J, Wadsworth FB, Lavallée Y, Bell AF, Main IG, Dingwell DB (2015) Heterogeneity: the key to failure forecasting. Sci Rep 5

Vasseur J, Wadsworth FB, Heap MJ, Main IG, Lavallée Y, Dingwell DB (2017) Does an inter-flaw length control the accuracy of rupture forecasting in geological materials? Earth Planet Sci Lett

Voight B (1988) A method for prediction of volcanic eruptions. Nature 332:125-130

Webb SL (1991) Shear and volume relaxation in $\mathrm{Na}_{2} \mathrm{Si}_{2} \mathrm{O}_{5}$. Am Mineral 76(9-10):1449-1454

Webb SL (1992) Low-frequency shear and structural relaxation in rhyolite melt. Phys Chem Mineral 19 (4):240-245

Webb SL, Dingwell DB (1990a) The onset of non-Newtonian rheology of silicate melts. Phys Chem Miner 17:125-132

Webb SL, Dingwell DB (1990b) Non-Newtonian rheology of igneous melts at high stresses and strain rates: experimental results for rhyolite, andesite, basalt, and nephelinite. J Geophys Res Solid Earth 95:1569515701

Zhang Y, Stolper EM, Wasserburg GJ (1991) Diffusion of a multi-species component and its role in oxygen and water transport in silicates. Earth Planet Sci Lett 103:228-240 
Open Access This chapter is distributed under the terms of the Creative Commons Attribution 4.0 International License (http://creativecommons.org/licenses/by/4.0/), which permits use, duplication, adaptation, distribution and reproduction in any medium or format, as long as you give appropriate credit to the original author(s) and the source, a link is provided to the Creative Commons license and any changes made are indicated.
The images or other third party material in this chapter are included in the work's Creative Commons license, unless indicated otherwise in the credit line; if such material is not included in the work's Creative Commons license and the respective action is not permitted by statutory regulation, users will need to obtain permission from the license holder to duplicate, adapt or reproduce the material.

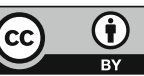

